\title{
Article \\ Phytosynthetic Fabrication of Lanthanum Ion-Doped Nickel Oxide Nanoparticles Using Sesbania grandiflora Leaf Extract and Their Anti-Microbial Properties
}

Srihasam Saiganesh ${ }^{1}$, Thyagarajan Krishnan ${ }^{2, *}$, Golla Narasimha ${ }^{3}$, Hesham S. Almoallim ${ }^{4}$, Sulaiman Ali Alhari ${ }^{5}$, Lebaka Veeranjaneya Reddy ${ }^{(\mathbb{D})}$, Koduru Mallikarjuna 7,8 ${ }^{D}$, Arifullah Mohammed ${ }^{9,10, *(\mathbb{D})}$ and Vattikuti S. V. Prabhakar 11,*

Citation: Saiganesh, S.; Krishnan, T.; Narasimha, G.; Almoallim, H.S; Alhari, S.A.; Reddy, L.V.; Mallikarjuna, K.; Mohammed, A.; Prabhakar, V.S.V. Phytosynthetic

Fabrication of Lanthanum Ion-Doped Nickel Oxide Nanoparticles Using Sesbania grandiflora Leaf Extract and Their Anti-Microbial Properties. Crystals 2021, 11, 124. https:// doi.org/10.3390/cryst11020124

Academic Editors: Leonid Kustov and Chinho Park

Received: 11 December 2020

Accepted: 23 January 2021

Published: 27 January 2021

Publisher's Note: MDPI stays neutral with regard to jurisdictional claims in published maps and institutional affiliations.

Copyright: (c) 2021 by the authors. Licensee MDPI, Basel, Switzerland. This article is an open access article distributed under the terms and conditions of the Creative Commons Attribution (CC BY) license (https:/ / creativecommons.org/licenses/by/ $4.0 /)$.
1 Department of Physics, JNTU Ananthapuramu, Anantapur 515002, India; srihasamsaiganesh@gmail.com 2 Department of Physics, JNTU College of Engineering Pulivendula, Pradesh 516390, India

3 Department of Virology, S. V. University, Tirupati 517502, India; gnsimha123ster@gmail.com

4 Department of Oral and Maxillofacial Surgery, College of Dentistry, King Saudi University, PO Box-60169, Riyadh-11545, Saudi Arabia; hkhalil@ksu.edu.sa

5 Department of Botany and Microbiology, College of Science, King Saudi University, PO Box-60169, Riyadh-11545, Saudi Arabia; sharbi@ksu.edu.sa

6 Department of Microbiology, Yogi Vemana University, Kadapa, Andhra Pradesh 516005, India; lvereddy@yahoo.com

7 Department for Management of Science and Technology Development, Ton Duc Thang University, Ho Chi Minh City 758307, Vietnam; koduru.mallikarjuna@tdtu.edu.vn

8 Faculty of Applied Sciences, Ton Duc Thang University, Ho Chi Minh City 758307, Vietnam

9 Faculty of Agro-Based Industry, Universiti Malaysia Kelantan, Jeli 17600, Malaysia

10 Institute of Food Security and Sustainable Agriculture, Universiti Malaysia Kelantan, Jeli 17600, Malaysia

11 School of Mechanical Engineering, Yeungnam University, 280 Daehak-ro, Gyeongsan-si, Gyeongsangbuk-do 38533, Korea

* Correspondence: ktrjntu@gmail.com (T.K.); aurifullah@umk.edu.my (A.M.); vsvprabu@gmail.com (V.S.V.P.)

Abstract: Over the past few years, the photogenic fabrication of metal oxide nanoparticles has attracted considerable attention, owing to the simple, eco-friendly, and non-toxic procedure. Herein, we fabricated $\mathrm{NiO}$ nanoparticles and altered their optical properties by doping with a rare earth element (lanthanum) using Sesbania grandiflora broth for antibacterial applications. The doping of lanthanum with $\mathrm{NiO}$ was systematically studied. The optical properties of the prepared nanomaterials were investigated through UV-Vis diffuse reflectance spectra (UV-DRS) analysis, and their structures were studied using $\mathrm{X}$-ray diffraction analysis. The morphological features of the prepared nanomaterials were examined by scanning electron microscopy and transmission electron microscopy, their elemental structure was analyzed by energy-dispersive X-ray spectral analysis, and their oxidation states were analyzed by X-ray photoelectron spectroscopy. Furthermore, the antibacterial action of $\mathrm{NiO}$ and La-doped $\mathrm{NiO}$ nanoparticles was studied by the zone of inhibition method for Gram-negative and Gram-positive bacterial strains such as Escherichia coli and Bacillus sublitis. It was evident from the obtained results that the optimized compound NiOLa-04 performed better than the other prepared compounds. To the best of our knowledge, this is the first report on the phytosynthetic fabrication of rare-earth ion Lanthanum $\left(\mathrm{La}^{3+}\right)$-doped Nickel Oxide $(\mathrm{NiO})$ nanoparticles and their anti-microbial studies.

Keywords: Sesbania grandiflora leaf extract; green synthesis; NiO nanoparticles; characterization; antibacterial activity

\section{Introduction}

Transition metal oxide nanoparticles (NPs), such as $\mathrm{Cu}_{2} \mathrm{O}, \mathrm{MnO}_{2}, \mathrm{NiO}, \mathrm{TiO}_{2}, \mathrm{Co}_{3} \mathrm{O}_{4}$, $\mathrm{SnO}_{2}$, and $\mathrm{Fe}_{2} \mathrm{O}_{3}$, are excellent candidates for use in electrocatalytic activity as they promote electron-transfer reactions and in medicinal applications. Among these, semiconductor 
nanoparticles such as $\mathrm{NiO}$ are promising materials in advanced research because of their utility in catalysis, gas sensors, and optoelectronics [1,2]. Metal oxides are low-cost materials for a wide range of optical applications and $\mathrm{NiO}$ is a p-type semiconductor with a wide bandgap (3.6-4.0 eV) [3,4]. Owing to its excellent chemical stability and its magnetic and optical properties, $\mathrm{NiO}$ has been tested as an active material for use in chemical sensors [5,6], pseudo-capacitor electrodes [7], photocathodes in dye-sensitized solar cells [8], catalysts [9], magnetic materials [10], and random-access memory devices [11,12]. Currently, several physical, chemical, biological, and hybrid methods are available for the synthesis of different types of metal oxide nanoparticles. The development of clean, non-toxic, and eco-friendly techniques has resulted in the observation of biological systems $[13,14]$. In particular, there has been more focus on plant-based materials, owing to their easy availability, low cost, and abundance of biomolecules such as polyphenols, flavonoids, proteins, terpenoids, and amines.

In the last decade, few attempts have been made to employ lanthanum doping of nanoparticle oxides. Numerous surface defects occur when $\mathrm{La}^{3+}$ ions are applied as doping elements, hindering the recombination of photo-induced electron-hole pairs. The recombination is hampered due to the creation of trap energy levels by the dopant. Similarly, $\mathrm{La}^{3+}$ ion-doped $\mathrm{TiO}_{2}$ nanoparticles have attracted significant attention in photocatalytic processes for the degradation of organic pollutants [15]. Moreover, $\mathrm{La}^{3+}$ absorbs light in the infrared region and can tune the bandgap of wide-bandgap materials such as $\mathrm{NiO}$. Recently, $\mathrm{La}^{3+}$ ion-doped $\mathrm{NiO}$ has attracted considerable attention, owing to its interesting applications. La-doped $\mathrm{NiO}$ nanofibers were synthesized by the electrospinning method and evaluated as potential electrode materials for application in high-performance supercapacitors and other applications [16-18].

Herein, the green synthesis of rare earth $(\mathrm{La})$ ion-doped $\mathrm{NiO}$ nanoparticles was carried out using Sesbania grandiflora leaf extract for antimicrobial studies, and their characteristics were analyzed. The optical properties of the La-doped $\mathrm{NiO}$ nanostructures were analyzed by UV-Vis diffuse reflectance spectroscopy (DRS), and their altered bandgaps were estimated. The structural properties of the prepared materials were observed by $X$-ray diffraction analysis. The morphological features of the prepared nanostructures were determined by scanning and electron microscopy. The chemical composition and oxidation states of elements were studied through X-ray photoelectron spectroscopy. Moreover, the prepared nanostructures were adopted for medicinal applications, and their efficiency in antibacterial activity was preliminarily studied.

\section{Materials and Methods}

\subsection{Synthesis of Lanthanum-Doped Nickel Oxide Nanoparticles}

Nickel chloride hexahydrate $\left(\mathrm{NiCl}_{2} \cdot 6 \mathrm{H}_{2} \mathrm{O}\right)$ (Sigma Aldrich, St. Louis, MO, USA), lanthanum (III) chloride heptahydrate $\left(\mathrm{LaCl}_{3} .7 \mathrm{H}_{2} \mathrm{O}\right)$, and $\mathrm{NaOH}$ were used to synthesize $\mathrm{NiO}$ nanoparticles (NPs). To prepare the La-doped $\mathrm{NiO}$ nanostructures, $2 \mathrm{~g}$ of $\mathrm{NiCl}_{2} \cdot 6 \mathrm{H}_{2} \mathrm{O}$ with various amounts of $\mathrm{LaCl}_{3} \cdot 7 \mathrm{H}_{2} \mathrm{O}(0,2,4,6,8$, and $10 \mathrm{wt} \%)$ was dissolved in $250 \mathrm{~mL}$ of distilled water to obtain a homogeneous solution at room temperature by constant highspeed stirring at $500 \mathrm{rpm}$. After solution was prepared, $25 \mathrm{~mL}$ of plant extract was added to the solution. Then, $2 \mathrm{M} \mathrm{NaOH}$ was added dropwise until the $\mathrm{pH}$ reached 12 , and stirring was continued for $6 \mathrm{~h}$. Finally, a green gel was formed, which was heated at $80{ }^{\circ} \mathrm{C}$ for $24 \mathrm{~h}$ to obtain a precipitate. The precipitate was washed with water and ethanol repeatedly and centrifuged to remove any residue or impurities. Subsequently, the obtained samples were annealed at $500{ }^{\circ} \mathrm{C}$ for $2 \mathrm{~h}$ to obtain pure nanoparticles [6].

Before NiO NP preparation, an extract was prepared from Sesbania grandiflora leaves. In a $1000 \mathrm{~mL}$ conical flask, $10 \mathrm{~g}$ of dried plant leaves was mixed with $500 \mathrm{~mL}$ of water, and the mixture was boiled for $5 \mathrm{~min}$ and decanted. Finally, the leaf extract was filtered and stored in a bottle for future use. 


\subsection{Characterization}

X-ray diffraction (XRD) analysis was used to characterize the crystalline nature of the nanostructures, and Bragg diffraction peaks were obtained using a PANalytical X'Pert PRO diffractometer equipped with $\mathrm{Cu}-\mathrm{K} \alpha$ radiation of $1.54 \AA$. The functional groups of biomolecules were confirmed by an attenuated total reflectance (ATR) mode Fourier transform infrared (FTIR) spectrophotometer (Thermo Scientific, Waltham, MA, USA) in the range $400-4000 \mathrm{~cm}^{-1}$. The optical properties of the prepared nanomaterials were studied using a UV-Vis-NIR spectrometer (Varian Cary 5000). The morphological features of the prepared nanomaterials were studied using scanning electron microscopy (SEM, S4800 Hitachi) and transmission electron microscopy (TEM, H-7600 Hitachi). The oxidation states of the elements were analyzed using an X-ray photoelectron spectrometer (XPS, Thermo Scientific, Waltham, MA, USA).

\subsection{Antimicrobial Activity}

The antibacterial activity of NiO NPs was studied using the zone inhibition method. Gram-positive and Gram-negative bacterial strains, E. coli and Bacillus spp., respectively, were selected as test organisms. The bacterial cultures were inoculated in Luria broth (liquid phase) in $100 \mathrm{~mL}$ conical flasks, and the flasks were incubated overnight at $37^{\circ} \mathrm{C}$. The overnight active Escherichia coli (E. coli) and Bacillus spp. cultures were seeded into Luria agar medium using spread plate techniques. Later in the Luria agar plates, cavities were made with the help of a metallic borer. All cavities were filled with $100 \mu \mathrm{L}$ of $\mathrm{NiO} \mathrm{NP}$ solution, and the petri plates were then incubated at $37^{\circ} \mathrm{C}$ overnight. The standard antibiotic streptomycin was used as a positive control. The zone of inhibition was measured using digital Vernier calipers, and the values were reported in centimeters [7].

\section{Results and Discussion}

\subsection{Structural Properties}

XRD analysis was used to investigate the crystal structure, lattice parameters, and crystallite sizes of $\mathrm{La}^{3+}$ ion-doped $\mathrm{NiO}$ nanoparticles. Figure 1a shows the XRD patterns of pure $\mathrm{NiO}$ and $\mathrm{La}^{3+}$ ion-doped $\mathrm{NiO}$ nanoparticles. The spectra show the presence of well-defined peaks attributable to the (111), (200), (220), and (311) planes, corresponding to the cubic $\mathrm{NiO}$ phase (JCPDS 040-835) [6]. Note here that no peaks related to other crystalline phases (such as $\mathrm{Ni}_{2} \mathrm{O}_{3}$ ) were found in these spectra at the resolution limit of the apparatus, indicating that the structure of $\mathrm{NiO}$ was not altered by lanthanum doping. In addition, there are no peaks associated with lanthanum oxide $\left(\mathrm{La}_{2} \mathrm{O}_{3}\right)$ or lanthanum nickel oxide $\left(\mathrm{LaNiO}_{3}\right)$ in the XRD spectra probably because of the low La content. The size of the particles at different doping concentrations can be calculated from the X-ray peaks of $\mathrm{La}^{3+}$ ion-doped $\mathrm{NiO}$ nanoparticles using the Scherrer formula [7]:

$$
\mathrm{D}=\mathrm{k} \lambda / \beta \cos \theta
$$

where $\mathrm{K}=$ the Scherrer constant (0.89), $\lambda=1.5406 \AA$ is the wavelength of the $\mathrm{Cu} \mathrm{K} \alpha$ line used by the instrument, and $\beta_{h k l}$ is the peak full width at half maximum can be calculated from a graph of intensity vs. diffraction angle $\theta$ of the $X$-rays. The average crystallite size values of $\mathrm{NiO}$ : La were found to vary between 23 and $10 \mathrm{~nm}$ (Figure $1 \mathrm{~b}$ ) depending on the $\mathrm{La}^{3+}$ ion content. This shows that doping with $\mathrm{La}$ inhibits the growth of crystallites, leading to a depressed crystallinity phenomenon. Moreover, the intensity of the diffraction peaks decreases, and the full width at half maximum increases, implying that the size of the crystallites decreases. As seen from the XRD pattern, the intensity of the peaks decreases with increasing lanthanum concentration, which may destroy the crystal structure. This decrease in grain size with doping can improve the performance of many nickel oxide-based devices. 


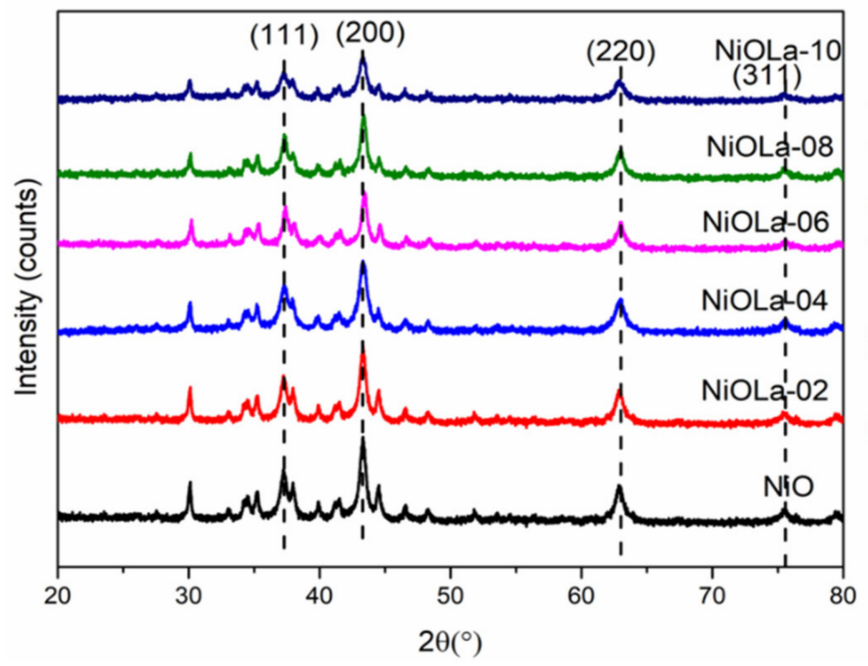

(a)

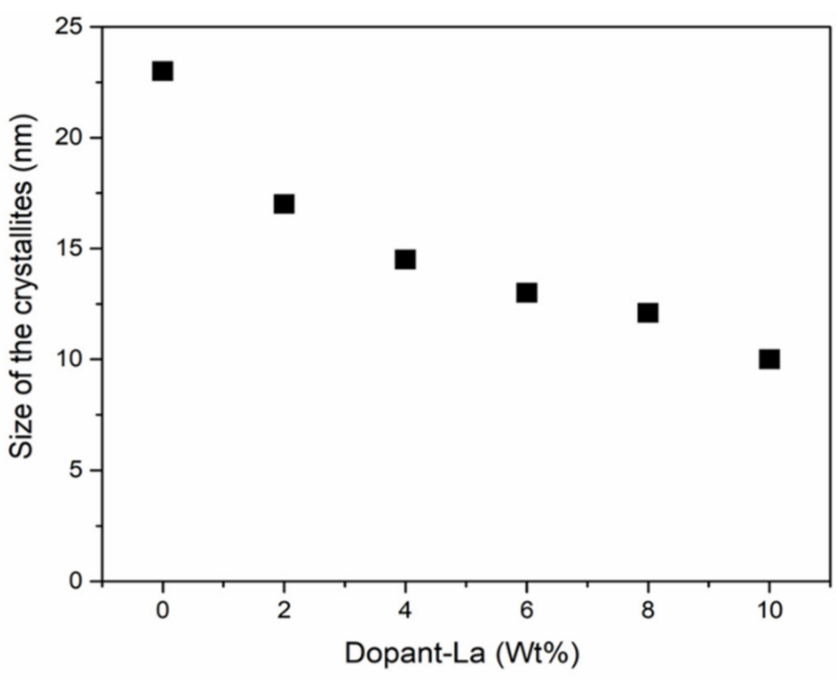

(b)

Figure 1. (a) X-ray diffraction analysis of $\mathrm{NiO}$ and $\mathrm{La}^{3+}$ ion-doped $\mathrm{NiO}$ nanoparticles. (b) Calculated average crystallite size with the dopant.

The average particle size decreases with increasing doping concentration, while the average strain increases [19]. Xu et al. [17] reported that La can be incorporated into metal (M) oxides by the formation of M-O-La bonds on the surface of small particles. This inhibits the movement of surface $\mathrm{Ni}$ atoms and results in coarser particles by restricting direct contact of neighboring crystallites, thus preventing the agglomeration of $\mathrm{NiO}$ nanoparticles and inhibiting coagulation.

\subsection{FTIR Analysis}

The FTIR spectra, shown in Figure 2, indicates the functional groups in the $\mathrm{La}^{3+}$ ion-doped $\mathrm{NiO}$ nanoparticles. The peak around $3299 \mathrm{~cm}^{-1}$ is due to symmetric and asymmetric $\mathrm{O}-\mathrm{H}$ stretching. The peak positioned at $1628 \mathrm{~cm}^{-1}$ is associated with carbonyl $\mathrm{C}=\mathrm{O}$ bending. The intense peak at $1320 \mathrm{~cm}^{-1}$ is attributed to the symmetric stretching of $\mathrm{C}-\mathrm{H}$. The carbonyl group stretching $(>\mathrm{C}=\mathrm{O})$ may cause the $\mathrm{NiO}$ nanoparticles to play a role in bridging networks [20]. The sharp peaks at $834 \mathrm{~cm}^{-1}$ are due to the combined effects of in-plane deformation of $\mathrm{NiO}$ and stretching vibrations of the metal oxide bonds (-M-O, M-La). The absorption bands at 995 and $1428 \mathrm{~cm}^{-1}$ are due to carbonate groups and that at $2995 \mathrm{~cm}^{-1}$ is due to $\mathrm{C}-\mathrm{H}$ stretching. After the sample was annealed at $500{ }^{\circ} \mathrm{C}$, the absorption band at $1421 \mathrm{~cm}^{-1}$ (Figure $2 \mathrm{~b}$ ) is still present, confirming its association with a carbonyl group. A significant peak at $436 \mathrm{~cm}^{-1}$ is due to the $\mathrm{Ni}-\mathrm{O}$ bond in the sample. The peaks at 485 and $865 \mathrm{~cm}^{-1}$ are associated with $\mathrm{Ni}-\mathrm{O}$ vibration and Ni-O$\mathrm{H}$ stretching, indicating bridging and non-bridging vibrations of these bonds. [21-23]. Moreover, after drying the sample, the peaks from the biomolecules disappeared, and the remaining carbon is associated with $\mathrm{NiO}$ or $\mathrm{NiOLa}$.

\subsection{Optical Properties}

The optical properties of lanthanum $\left(\mathrm{La}^{3+}\right)$ ion-doped $\mathrm{NiO}$ nanoparticles and pristine $\mathrm{NiO}$ nanoparticles were studied. Absorption spectra were recorded by a UV-Vis-NIR spectrometer in the range $200-750 \mathrm{~nm}$, as shown in Figure 3a. From the spectra, it can be seen that the absorption band is slightly shifted towards a higher wavelength (redshift) with $\mathrm{La}^{3+}$ addition, which denotes the formation of trap energy levels due to the dopant atoms. When the concentration of La is $2-10 \mathrm{wt} \%$, the absorption intensity also increases with increasing $\mathrm{La}^{3+}$ ion concentration. 


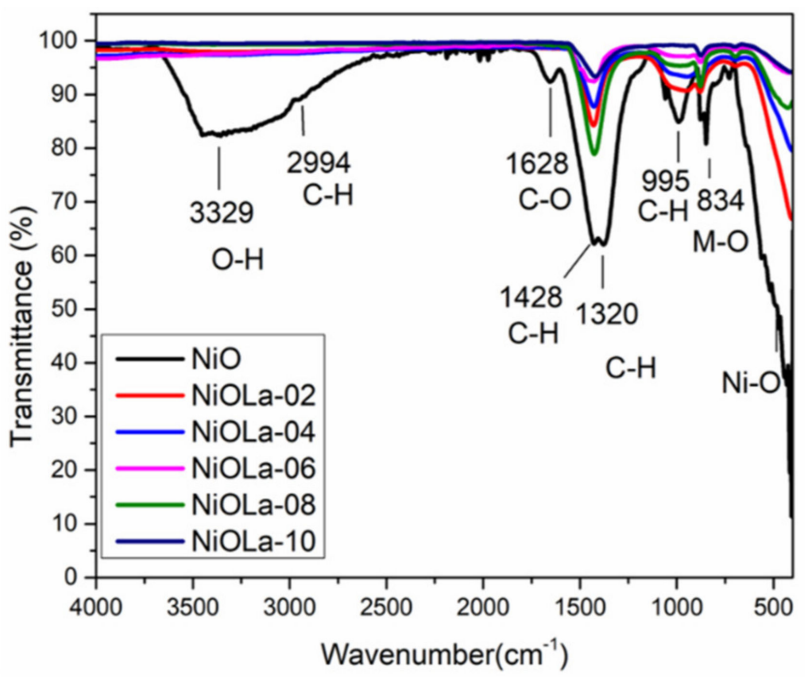

(a)

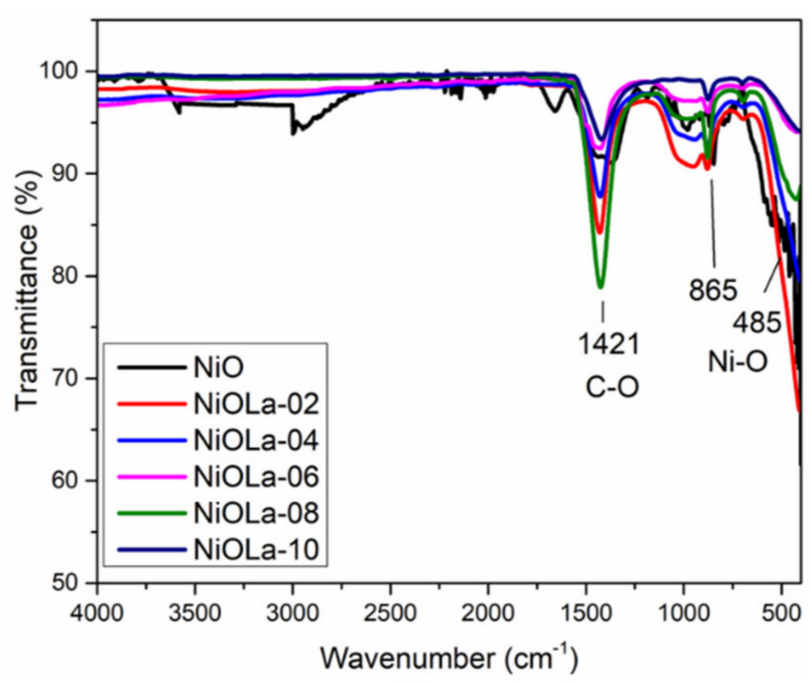

(b)

Figure 2. FTIR spectra of $\mathrm{La}^{3+}$ ion-doped $\mathrm{NiO}$ nanoparticles: (a) before annealing; (b) after annealing.

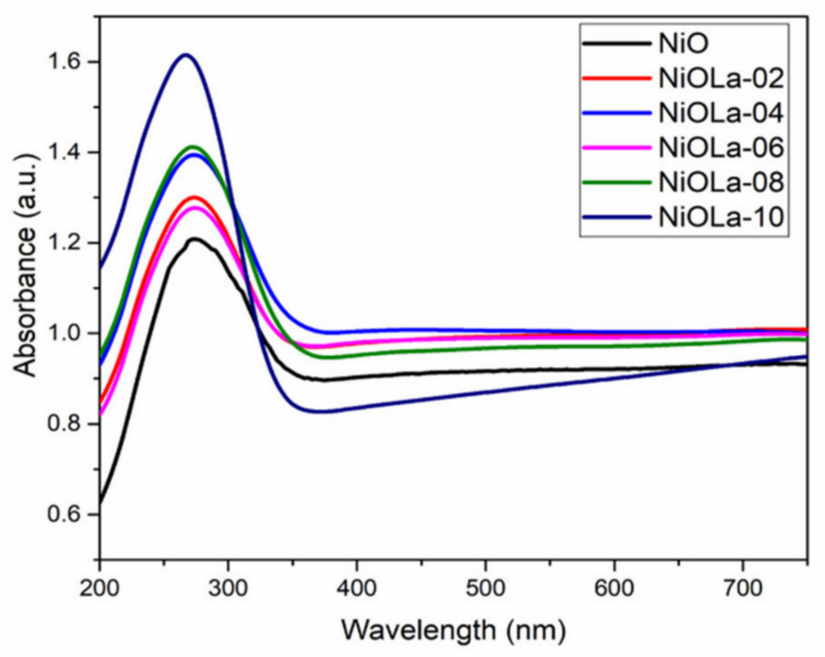

(a)

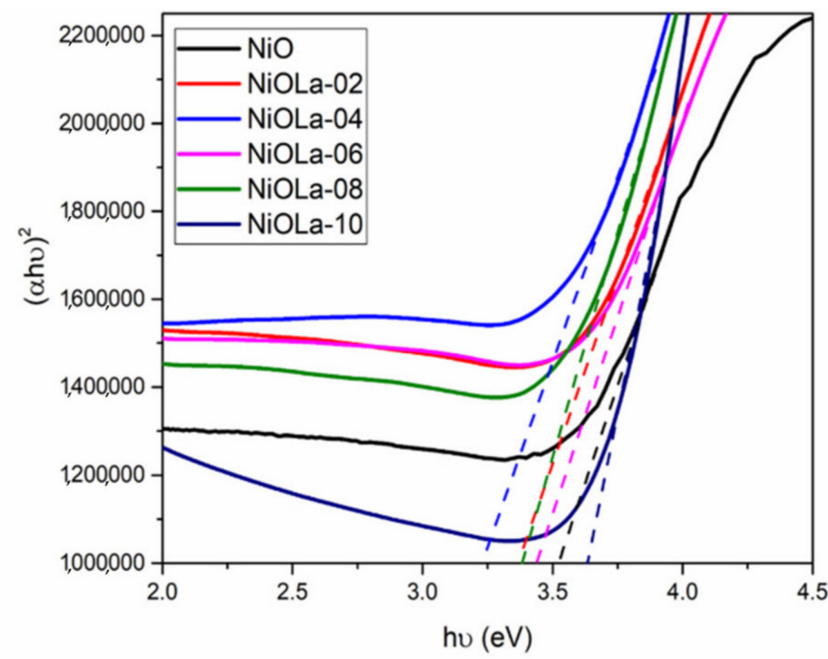

(b)

Figure 3. (a) UV-Vis spectra of $\mathrm{NiO}$ and $\mathrm{La}^{3+}$ ion-doped $\mathrm{NiO}$ nanoparticles. (b) The energy gap between $\mathrm{NiO}$ and $\mathrm{La}^{3+}$ ion-doped $\mathrm{NiO}$ nanoparticles.

In the UV-Visible-absorption spectra, the characteristic band edges are shifted towards lower energy regions (Figure $3 b$ ), which, due to quantum confinement, may have caused the absorbed wavelength to shift to a lower energy state with an increase in the doping concentration. As the concentration of lanthanide ions increases, the fundamental absorption edge tends to shift to higher wavelengths. In addition, the shift of the absorption band to lower energy could be attributed to the decreasing formation of non-bridging oxygen, which binds the electrons from formless energy in non-bridging oxygen to bridging oxygen [24-27]. It can be seen that the maximum absorption edge of the $\mathrm{La}^{3+}$ ion-doped $\mathrm{NiO}$ nanoparticles appears to be at $272 \mathrm{~nm}$. The energy gap of the $\mathrm{La}^{3+}$ ion-doped $\mathrm{NiO}$ nanoparticles can be determined using the Tauc relation [4].

$$
(\alpha \mathrm{h} v)^{\mathrm{n}}=\mathrm{A}(\mathrm{h} v-\mathrm{Eg})
$$

where $n$ is a number depending on the nature of the transition process, and $A$ is the coefficient of absorbance. For direct transition, $n=2$, and for an indirect transition, $n=0.5$. Therefore, the direct bandgap of $\mathrm{La}^{3+}$ ion-doped $\mathrm{NiO}$ nanoparticles can be obtained by 
extrapolating the linear portion of the $(\alpha \mathrm{h} v)^{2}$ versus $\mathrm{h} v$ curve to the energy axis, as shown in Figure $3 b$. The bandgap of $\mathrm{La}^{3+}$ ion-doped $\mathrm{NiO}$ nanoparticles calculated from this plot is between 3.17 and $3.79 \mathrm{eV}$, increasing with a higher concentration of the $\mathrm{La}^{3+}$ ion [28].

The value of the direct energy bandgap $\left(\mathrm{E}_{\mathrm{g}}\right)$ can be obtained from the intercepts by extrapolating the linear portion of the curve to the linear axis representing the photon energy. The optical bandgaps of the direct and indirect bandgaps depend on changes in the structure of the former $(\mathrm{NiO})$ with the modifier $\left(\mathrm{La}^{3+}\right)$. The formation of $\mathrm{NiO}$ leads to tight binding of oxygen anions to the host materials. Hence, the optical band gap decreases with an increasing number of bridging $\mathrm{La}^{3+}$ ions in the network system. Moreover, the decreasing value of the optical bandgap might be due to the increasing number of non-bridging oxygens [29-31].

\subsection{Morphological Analysis}

The morphological features of prepared nanoparticles were analyzed by SEM and the obtained results are shown in Figure 4. The SEM images reveal the typical nanostructure of La-doped $\mathrm{NiO}$ with spherical and other irregular shapes. The nanoparticles appear to be spherical or cubical, as shown in the SEM images of Figure 4. In the existing literature, spherical nanoparticles have been reported using a green synthesis method [30-32]. EDS analysis confirms that $\mathrm{La}^{3+}$ ions are doped into $\mathrm{NiO}$ nanoparticles, as shown in Figure $4 \mathrm{~g}$. The size of the nanoclusters was difficult to estimate from the SEM images in Figure 4. Some of the nanoparticles become agglomerated after the annealing process, as an effect of the heating. The distribution of nanoparticles (NiOLa-04) was easier to observe by TEM analysis, and the results are shown in Figure 5. The prepared nanoparticles have very small spherical and cubical structures and few are agglomerated nanoparticles. Generally, the size and shape of nanoparticles play a significant role in catalytic applications and other chemical/biological applications owing to their large surface area.

\subsection{XPS Analysis}

The oxidation states and chemical composition of the prepared La-doped nanostructures (NiOLa-04) were determined by XPS, and the results are presented in Figure 6. The survey scan (Figure 6a) shows the presence of $\mathrm{C}, \mathrm{N}, \mathrm{O}, \mathrm{Ni}$, and $\mathrm{La}$ in the fabricated sample. The deconvoluted components of carbon (Figure $6 \mathrm{~b}$ ) are denoted as $\mathrm{C} 1(284.2 \mathrm{eV})$, $\mathrm{C} 2(284.8 \mathrm{eV}), \mathrm{C} 3(287.9 \mathrm{eV}), \mathrm{C} 4(288.9 \mathrm{eV})$, and C5 $(293.0 \mathrm{eV})$. The binding energies of 284.2 and $284.8 \mathrm{eV}$ represent non-oxygenated hydrocarbons with $\mathrm{C}-\mathrm{H} \mathrm{sp} \mathrm{sp}^{2}$ and $\mathrm{sp}^{3}$ bonds from biomolecules. The peaks at 287.9 and $288.9 \mathrm{eV}$ correspond to carbonyl and carboxylic groups in biomolecules, respectively, which are strongly bound to the surface of the prepared nanoparticles. Moreover, the carbon peaks also suggest carboxylic C-O-Ni linkages, where biomolecules derived from leaf extract may act as capping agents. Furthermore, the broad spectrum (Figure 6c) of La contains doublet peaks La1 and La2 at 834.4 and $837.9 \mathrm{eV}$, respectively, owing to $\mathrm{La} 3 \mathrm{~d}$, indicating the presence of La in the prepared sample. The deconvoluted spectrum of $\mathrm{Ni}$ (Figure 6d) contains six peaks, which are represented as $\mathrm{Ni1}(853.4 \mathrm{eV}), \mathrm{Ni2}(855.4 \mathrm{eV})$-attributed to the doublet of $\mathrm{Ni}^{2+} 2 \mathrm{p} 3 / 2$, and a satellite peak observed at $860.5 \mathrm{eV}(\mathrm{Ni3})$; peaks at $870.6 \mathrm{eV}(\mathrm{Ni} 4), 872.5 \mathrm{eV}$ (Ni5)—ascribed to $\mathrm{Ni}^{2+} 2 \mathrm{p}$ $1 / 2$, and its satellite peak located at $878.6 \mathrm{eV}$ (Ni6), which strongly support the formation of NiO NPs $[33,34]$. The deconvoluted peaks (Figure 6e) O1 $(529.5 \mathrm{eV}), \mathrm{O} 2(530.8 \mathrm{eV})$, and $\mathrm{O} 3(535.2 \mathrm{eV})$ can be attributed to the oxygen in $\mathrm{NiO}$, with $\mathrm{O} 2$ and $\mathrm{O} 3$ representing $\mathrm{Ni}-\mathrm{O}-\mathrm{Ni} / \mathrm{Ni}-\mathrm{O}-\mathrm{C}$, i.e., carboxylic group-containing functional groups of biomolecules such as protein groups in the leaf extract bonding with $\mathrm{Ni}$. 


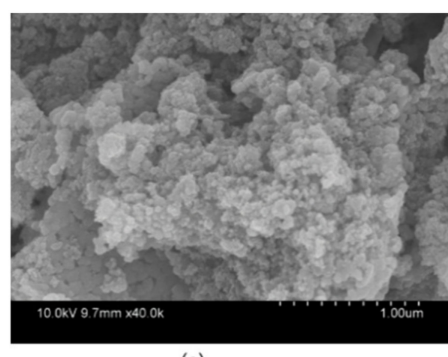

(a)

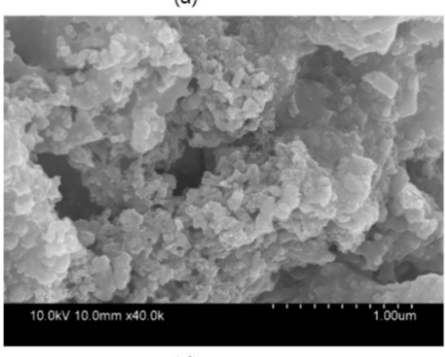

(d)
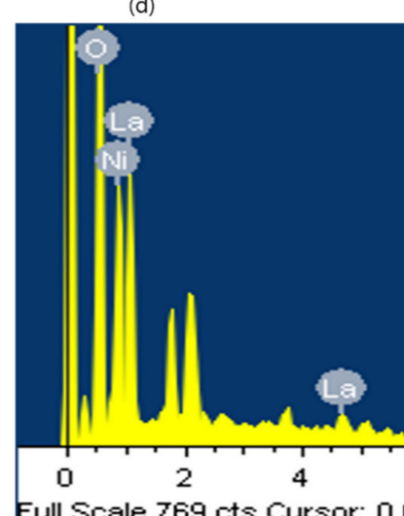

Full Scale 769 cts Cursor: 0.000

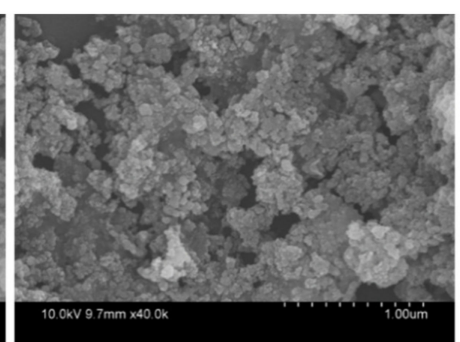

(b)

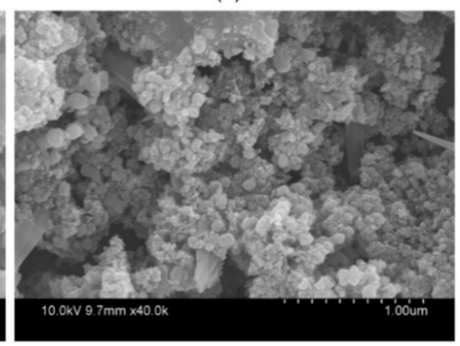

(e)

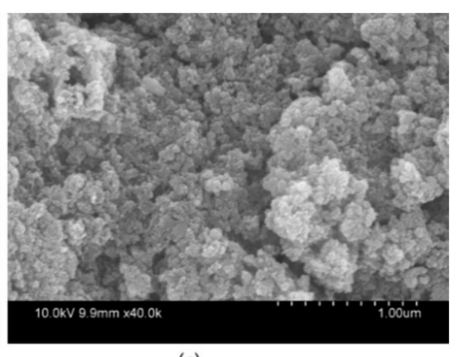

(c)

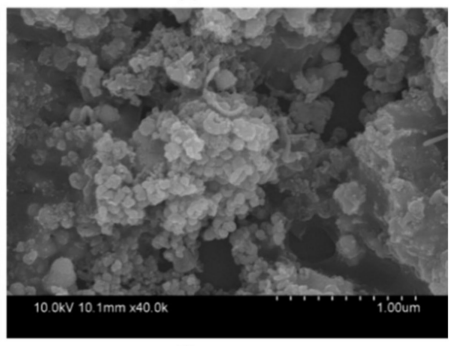

(f)

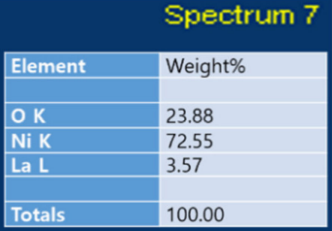

Totals $\quad 100.00$

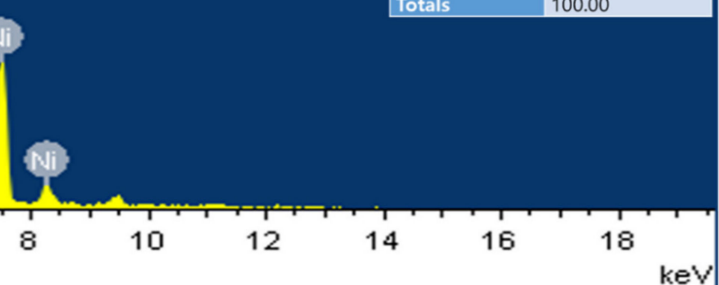

(g)

Figure 4. SEM images and EDS spectrum of prepared nanostructures (a) NiO, (b) NiO-La-02, (c) NiOLa-04, (d) NiOLa-06, (e) NiOLa-08, and (f) NiOLa-10, and (g) EDS spectrum of NiOLa-04 nanoparticles.

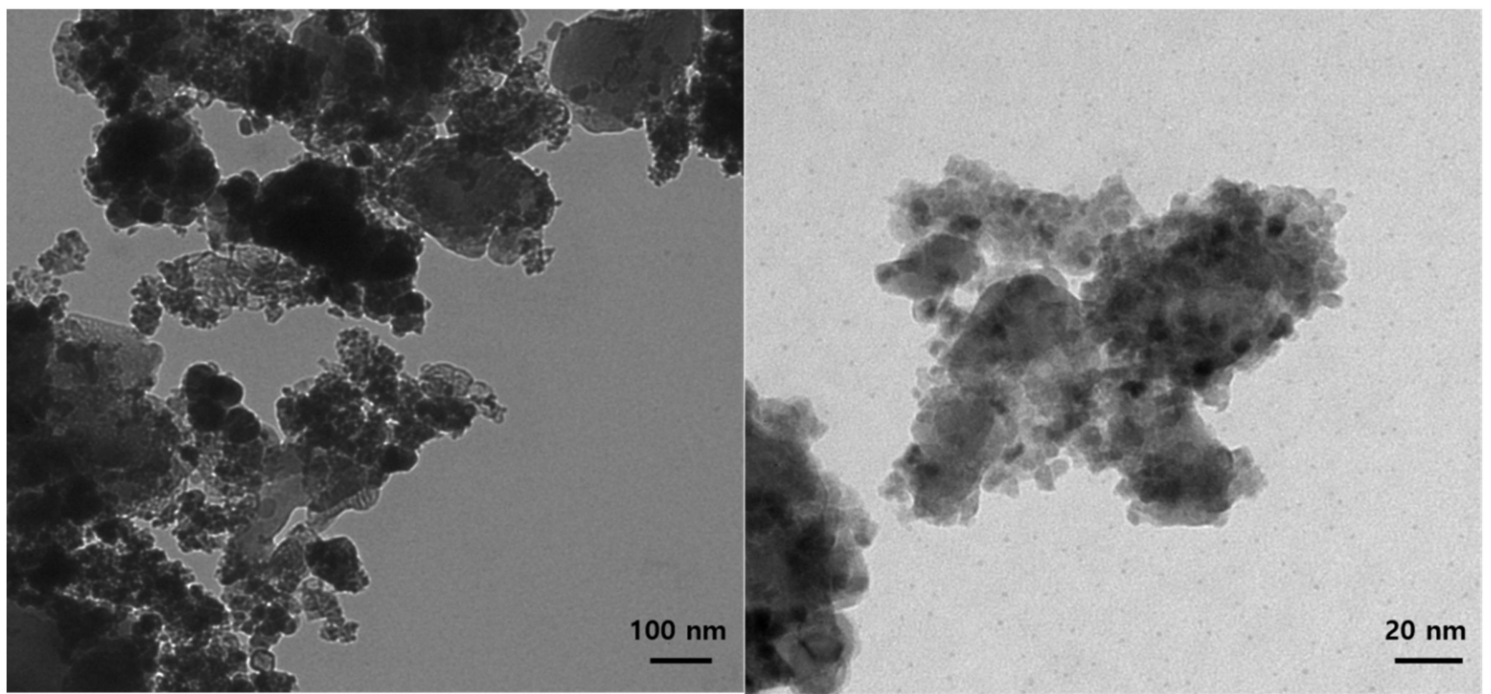

(a)

(b)

Figure 5. TEM images of NiOLa-04 nanoparticles: (a) $100 \mathrm{~nm}$ magnification; (b) $20 \mathrm{~nm}$ magnification. 


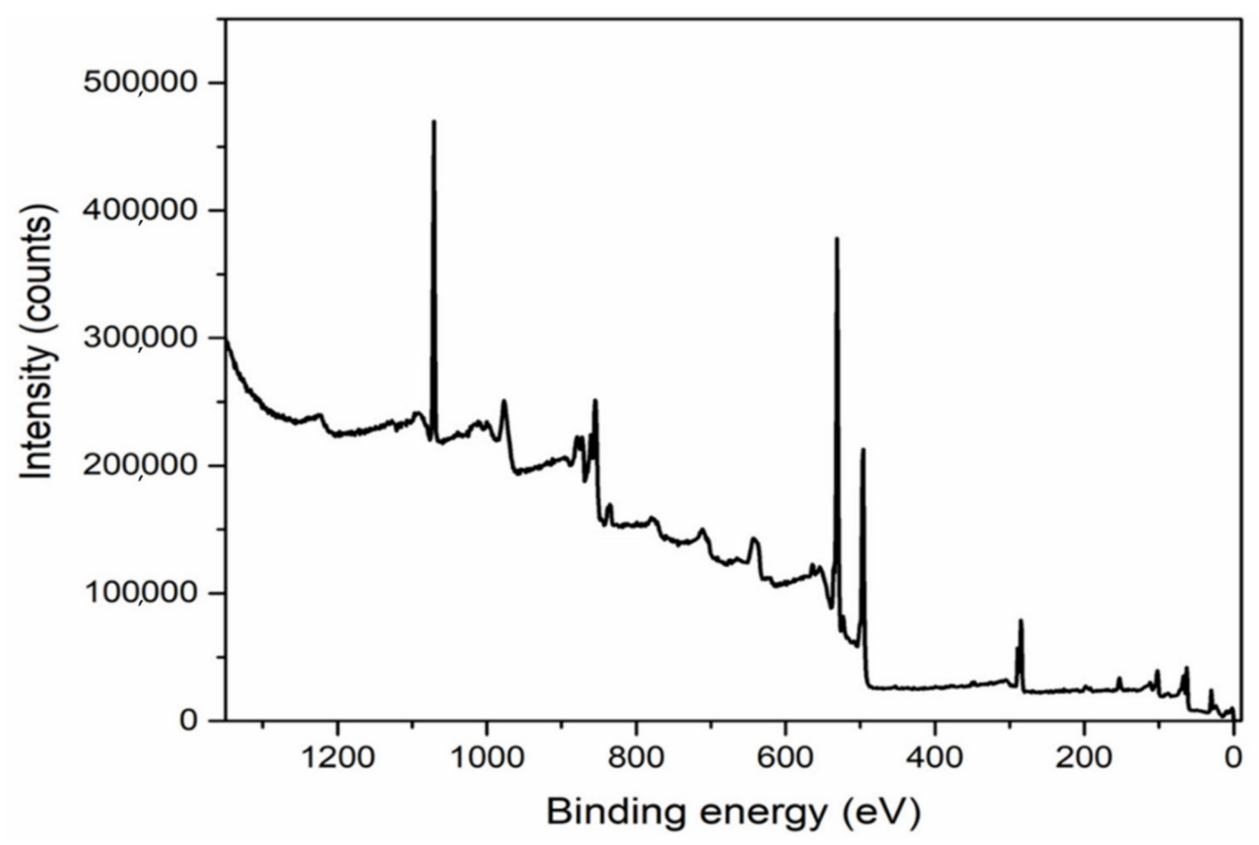

(a)

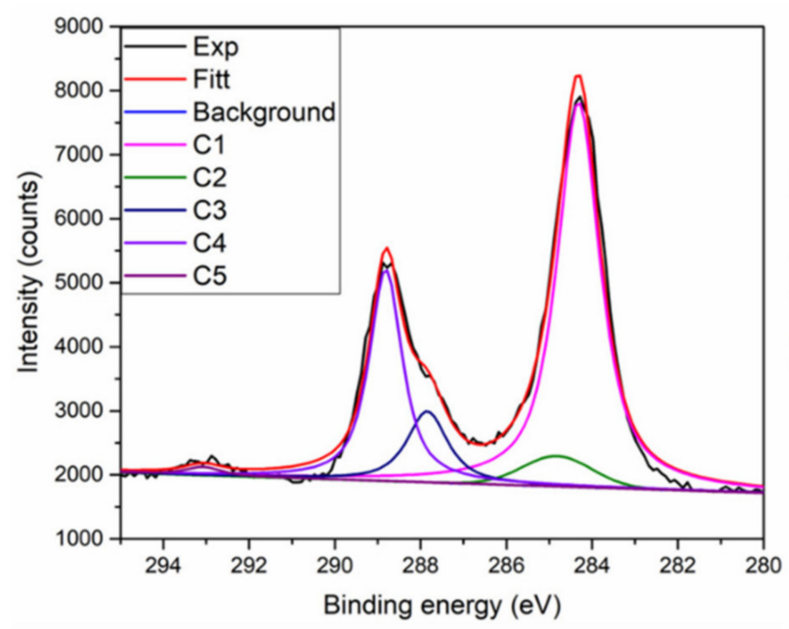

(b)

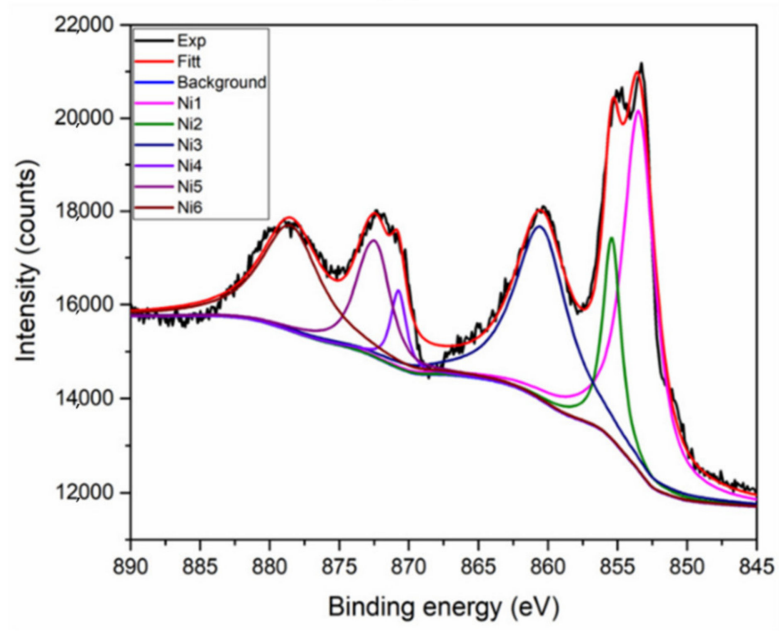

(d)

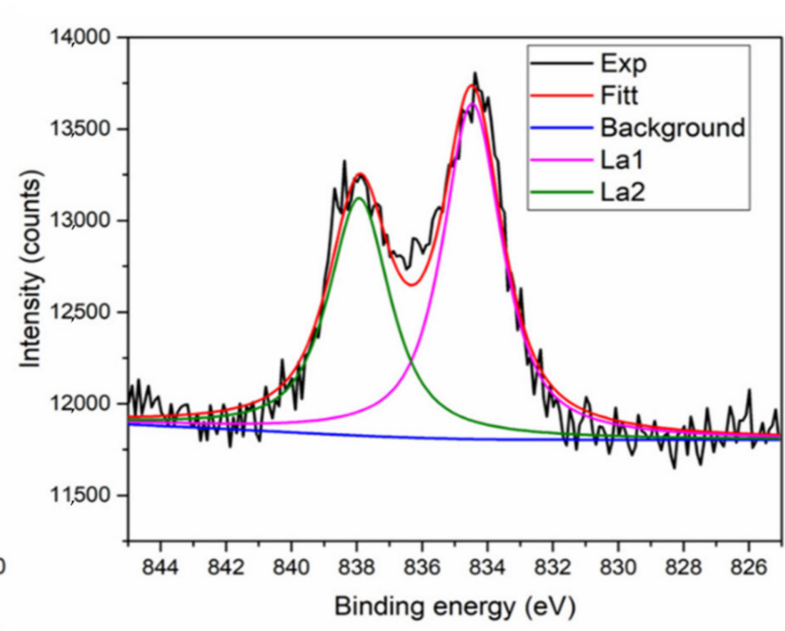

(c)

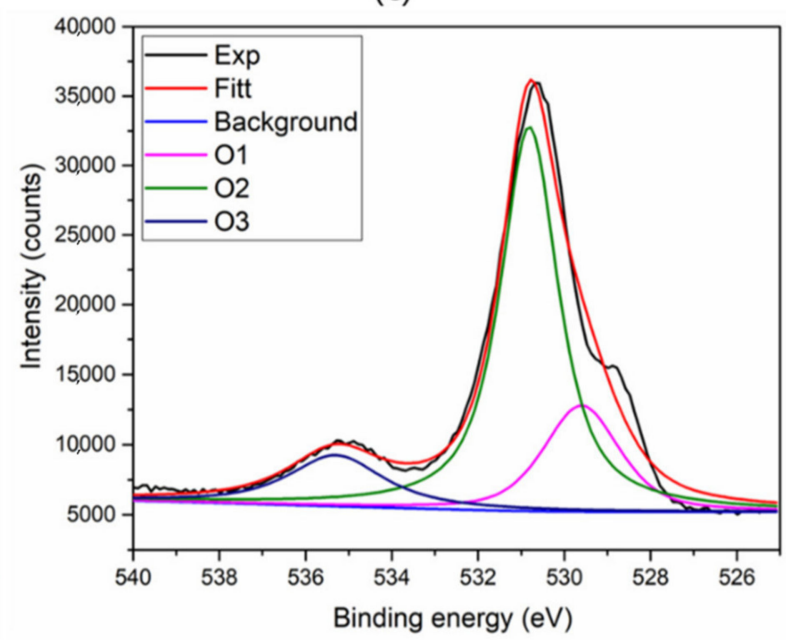

(e)

Figure 6. XPS spectra of NiOLa-04 nanoparticles: (a) survey scan; (b) carbon; (c) lanthanum; (d) nickel; and (e) oxygen elements. 


\subsection{Antibacterial Activity}

The antibacterial activity of NiO NPs was studied using the zone inhibition method and both Gram-positive and Gram-negative bacterial strains, E. coli and Bacillus spp., respectively, were used as test organisms. The antimicrobial and antifungal activities of nanoparticles depend on the physicochemical properties of nanoparticles and the type of bacteria and fungi, which can significantly affect the functions of the bacterial cell. Bacillus spp. are nonpathogenic bacteria and contain a thicker peptidoglycan (PG) layer; therefore, the toxicity of NiO NPs is less than that of Bacillus spp., as shown in Table 1.

Table 1. Antibacterial activity of $\mathrm{La}^{3+}$ ion-doped Nio nanoparticles.

\begin{tabular}{|c|c|c|}
\hline Sample & Microorganisms & Zone of Inhibition $(\mathrm{cm})$ \\
\hline \multirow{3}{*}{ Pure $\mathrm{NiO}$} & Bacillus subtilis & 0.65 \\
\hline & Escherichia coli & 0.80 \\
\hline & Bacillus subtilis & 0.8 \\
\hline \multirow{2}{*}{$\mathrm{NiOLaO}_{2}$} & Escherichia coli & 0.9 \\
\hline & Bacillus subtilis & 1.0 \\
\hline \multirow[t]{2}{*}{$\mathrm{NiOLaO}_{4}$} & Escherichia coli & 1.15 \\
\hline & Bacillus subtilis & 0.85 \\
\hline \multirow[t]{2}{*}{$\mathrm{NiOLaO}_{6}$} & Escherichia coli & 1.0 \\
\hline & Bacillus subtilis & 1.25 \\
\hline $\begin{array}{l}\text { Standard antibiotic } \\
\text { Streptomycin (AB) }\end{array}$ & Escherichia coli & 1.4 \\
\hline
\end{tabular}

By observing the inhibition zones, it can be stated that $\mathrm{La}^{3+}$ ion-doped NiO NPs exhibit good antibacterial activity against the Gram-positive and Gram-negative bacterial strains (Table 1). The maximum sizes of the inhibition zone observed for the $4 \%$ La sample against Gram-positive Bacillus spp. and Gram-negative E. coli bacterial strains, grown in nutrient agar medium, are $1.00 \mathrm{~cm}$ and $1.15 \mathrm{~cm}$, respectively, similar to those of the standard antibiotic streptomycin.

Owing to their nano size and stability, the NPs showed better antibacterial activity in the present study. The small size usually enhances fusibility and penetration into the intracellular matrix, interacting with intracellular $\mathrm{Ca}^{2+}$ absorption, and causing cell damage. Attachment of nanoparticles with a reduced size initiates electrostatic interactions between the La-doped nickel ions released from the NPs and the cell membrane of the microbes, which causes cell membrane damage. A damaged cell membrane is more sensitive to further reactions and allows for the penetration of nanoparticles and the outflow of intracellular organelles. These sequential steps improve the inhibitory activity of the nanoparticles. A theoretical antimicrobial mechanism of NiO-NPs has been previously reported $[35,36]$. The penetration of NiO-NPs inside the microbial cell further enhances microbial inhibition by interacting with the electron transport and destroying DNA by separating the phosphate and hydrogen bonds, denaturing the protein by modifying the tertiary structure, and damaging the mitochondria by oxidative stress, generating reactive oxygen species (ROS) from interactions between the inorganic metal and La-doped $\mathrm{NiO}$ nanoparticles, which finally leads to cell death. The antibacterial activity is mainly governed by the size, phase, concentration, stability, and morphology of the nanoparticles, and reaction time. Hence, the activity and stability of La-doped NiO NPs are very effective against common pathogens and can also be utilized as an effective catalyst in wastewater treatment as an alternative to the bleaching process.

\section{Conclusions}

In summary, La-doped $\mathrm{NiO}$ nanoparticles were successfully synthesized in Sesbania grandiflora leaf extract. The $\mathrm{NiO}$ nanoparticle crystallinity decreased with increasing dopant concentration, which led to a decrease in the particle size, as indicated by XRD analysis. SEM analysis revealed that the $\mathrm{NiO}$ nanoparticles possessed spherical and irregular shapes, and the size of the particles was decreased by increasing $\mathrm{La}^{3+}$ ion doping concen- 
tration. For a concentration of $4 \% \mathrm{La}^{3+}$ ion-doped $\mathrm{NiO}$ nanoparticles, the direct bandgap was calculated to be $3.17 \mathrm{eV}$. The NiOLa-04 nanoparticles show appreciable antibacterial activity against both Gram-positive and Gram-negative bacteria; hence, these nanoparticles could be used as an effective bioremediation and as an antibacterial agent in current nanomedicine.

Author Contributions: S.S. performed the experiments; T.K. reviewed the manuscript and supervised the work; G.N. performed the antimicrobial experiments; H.S.A. and S.A.A. provided resources and funding; L.V.R. edited the manuscript; K.M. wrote the original manuscript; A.M. analyzed the data and supervised the work; V.S.V.P. provided instrumentation facility and edited the manuscript. All authors have read and agreed to the published version of the manuscript.

Funding: This research received no external funding.

Institutional Review Board Statement: Not applicable.

Informed Consent Statement: Not applicable.

Data Availability Statement: Data available on request due to restrictions e.g., privacy or ethical.

Acknowledgments: This project was supported by researchers supporting the project number (RSP2020/283), King Saud University Riyadh, Saudi Arabia.

Conflicts of Interest: The authors declare no conflict of interest.

\section{References}

1. Rahdar, A.; Aliahmad, M.; Azizi, Y. NiO Nanoparticles: Synthesis and Characterization. J. Nanostruct. $2015,5,145-151$.

2. Manigandan, R.; Giribabu, K.; Suresh, R.; Munusamy, S.; Praveen Kumar, S.; Muthamizh, S.; Stephen, A.; Narayanan, V. Characterization and Photocatalytic Activity of Nickel oxide nanoparticles. Int. J. ChemTech Res. 2014, 6, 3395-3398.

3. Sahu, R. Synthesis of Neodymium Doped in Nickel Oxide for Nano-Compound. Synthesis 2018, 5, $241-244$.

4. Fasaki, I.; Kandyla, M.; Kompitsas, M. Properties of pulsed laser deposited nanocomposite NiO:Au thin films for gas sensing applications. Appl. Phys. A 2012, 107, 899-904. [CrossRef]

5. Hotovy, I.; Huran, J.; Siciliano, P.; Capone, S.; Speiss, L.; Rehacek, V. Enhancement of $\mathrm{H}_{2}$ sensing properties of NiO-based thin films with a Pt surface modification. Sens. Actuators B 2004, 103, 300-311. [CrossRef]

6. Vijayakumar, S.; Nagamuthu, S.; Muralidharan, G. Supercapacitor studies on NiO nanoflakes synthesized through a microwave route. ACS Appl. Mater. Interfaces 2013, 5, 2188-2196. [CrossRef]

7. Wong, K.K.; Vikram, P.; Chiruvella, K.K.; Mohammed, A. Phytochemical screening and antimicrobial potentials of Borreria sps (Rubiaceae). J. King Saud Univ. Sci. 2015, 27, 302-311. [CrossRef]

8. Nattestad, A.; Mozer, A.J.; Fischer, M.K.; Cheng, Y.B.; Mishra, A.; Baeuerle, P.; Bach, U. Highly efficient photocathode's for dye-sensitized tandem solar cells. Nat. Mater. 2010, 9, 31-35. [CrossRef]

9. Jana, S.; Samai, S.; Mitra, B.C.; Bera, P.; Mondal, A. Nickel oxide thin film from electrodeposited nickel sulfide thin film: Peroxide sensing and photo-decomposition of phenol. Dalton Trans. 2014, 43, 13096-13104. [CrossRef]

10. Granqvist, C.G.; Niklasson, G.A.; Azens, A. Electrochromics: Fundamentals and energy-related applications of oxide-based devices. Appl. Phys. A 2007, 89, 29-35. [CrossRef]

11. Ghosh, M.; Biswas, K.; Sundaresan, A.; Rao, C.N.R. MnO and NiO nanoparticles: Synthesis and magnetic properties. J. Mater. Chem. 2006, 16, 106-111. [CrossRef]

12. Akinaga, H.; Shima, H. Resistive random access memory (ReRAM) based on metal oxide. Proc. IEEE 2010, 98, 2237-2251. [CrossRef]

13. Park, J.W.; Park, J.W.; Kim, D.Y.; Lee, J.K. Reproducible resistive switching in non-stoichiometric nickel oxide films grown by rf reactive sputtering for resistive random access memory applications. J. Vac. Sci. Technol. A 2005, 23, 1309-1313. [CrossRef]

14. Korake, P.V.; Dhabbe, R.S.; Kadam, A.N.; Gaikwad, Y.B.; Garadkar, K.M. Highly active lanthanum doped ZnO nanorods for photodegradation of metasystox. J. Photochem. Photobiol. B 2014, 130, 11-19. [CrossRef] [PubMed]

15. Jia, J.; Luo, F.; Gao, C.; Suo, C.; Wang, X.; Song, H.; Hu, X. Synthesis of La-doped NiO nanofibers and their electrochemical properties as electrode for supercapacitors. Ceram. Int. 2014, 40, 6973-6977. [CrossRef]

16. Dakhel, A.A. Dielectric relaxation behaviour of Li and La co-doped NiO ceramics. Ceram. Int. 2013, 39, 4263-4268. [CrossRef]

17. Xia, X.; Ping Tu, J.; Mai, Y.; Chen, R.; Wang, X.; Gu, C.; Zhao, X. Graphene Sheet/Porous NiO Hybrid Film for Supercapacitor Applications. Chemistry 2011, 17, 10898-10905. [CrossRef]

18. Xu, A.W.; Gao, Y.; Liu, H.Q. The Preparation, Characterization, and Their Photocatalytic Activities of Rare-Earth-Doped Tio2 Nanoparticles. J. Catal. 2002, 207, 151-157. [CrossRef]

19. Deshpande, M.P.; Patel, K.N.; Gujarati, V.P.; Patel, K.; Chaki, S.H. Structural, thermal and optical properties of NiO nanoparticles Synthesized by Chemical precipitation method. Adv. Mater. Res. 2016, 1141, 65-71. [CrossRef] 
20. Pal, M.; Pal, U.; Jiménez, J.M.; Pérez-Rodríguez, F. Effects of crystallization and dopant concentration on the emission behavior of $\mathrm{TiO}_{2}$ : Eu nanophosphors. Nanoscale Res. Lett. 2012, 3, 1. [CrossRef]

21. Sai Ganesh, S.; Rajesh, S.; Thyagarajan, K. Synthesis and Structural Properties of ZnO Nanoparticles by Alternanthera Sessile Leaves Extract. Int. J. Adv. Res. 2017, 5, 885-889. [CrossRef]

22. Agale, A.A.; Dighore, N.R.; Janjal, S.M.; Gaikwad, S.T.; Rajbhoj, A.S. Size Determination of Nickel Oxide Nanoparticles by Electrochemical Reduction Method and Its Antibacterial Activity. World J. Pharm. Res. 2015, 4, 1189-1200.

23. Sarma, H.; Sarma, K.C. X-ray Peak Broadening Analysis of ZnO Nanoparticles Derived by Precipitation method. Int. J. Sci. Res. Publ. 2014, 4, 1-7.

24. Han, D.; Jing, X.; Wang, J.; Yang, P.; Song, D.; Liu, J. Porous lanthanum doped NiO microspheres for supercapacitor application. J. Electroanal. Chem. 2012, 682, 37-44. [CrossRef]

25. Ramasami, A.K.; Reddy, M.V.; Balakrishna, G.R. Combustion synthesis and characterization of NiO nanoparticles. J. Mat. Sci. Semicond. Proc. 2015, 40, 194-202. [CrossRef]

26. Joseph, D.P.; Saravanan, M.; Muthuraaman, B.; Renugambal, P.; Sambasivam, S.; Philip Raja, S.; Maruthamuthu, P.; Venkateswaran, C. Spray deposition and characterization of nanostructured Li doped $\mathrm{NiO}$ thin films for application in dye-sensitized solar cells. Nanotechnology 2008, 19, 485707. [CrossRef]

27. Amor, M.B.; Boukhachem, A.; Boubaker, K.; Amlouk, M. Structural, optical and electrical studies on Mg-doped NiO thin films for sensitivity applications. J. Mat. Sci. Semicond. Proc. 2014, 27, 994-1006. [CrossRef]

28. Kamarthi, A.; Shanigarapu, S. Green Synthesis of Nickel Nanoparticles from Extract of Coriandrum Sativum Leaves along with Comparative Analysis using Chemical Reduction Method. Int. J. Res. Advent Technol. 2018, 6, 2279-2286.

29. Ezhilarasi, A.A.; Vijaya, J.J.; Kaviyarasu, K.; Kennedy, L.J.; Ramalingam, R.J.; Al-Lohedan, H.A. Green synthesis of NiO nanoparticles using Aegle marmelos leaf extract for the evaluation of in-vitro cytotoxicity, antibacterial and photocatalytic properties. J. Photochem. Photobiol. B 2018, 180, 39-50. [CrossRef]

30. Sai Ganesh, S.; Thyagarajan, K. Synthesis and characterization of NiO nanoparticles from sesbania grandiflora leaf extract. Biotechnol. Bioeng. Proc. ICBT 2017, 568-572.

31. Perachiselvi, M.; Jenson Samraj, J.; Sakthi Bagavathy, M.; Arthi Feiona, T.; Krishnaveni, P.; Pushpa Laksmi, E.; Swetha, V.; Margreet Leema, M.; John Britto, S.; Annadurai, G. Fabrication of Nickel Oxide Nanoparticles for Antibacterial and Photocatalytic Activity. RJLBPCS 2018, 4, 749-760.

32. Ayesha Mariam, A.; Kashif, M.; Arokiyaraj, S.; Bououdina, M.; Sankaracharyulu, M.G.V.; Jayachandran, M.; Hashim, U. Bio-Synthesis of $\mathrm{NiO}$ and Ni Nanoparticles and Their Characterization. Digest J. Nanomater. Biostruct. 2014, 9, 1007-1019.

33. Nandapure, B.I.; Kondawar, S.B.; Chaudhari, A.M.; Jamkar, D.V. Synthesis and Characterization of Nickel Oxide Nanoparticles with Wide Band Gap Energy Prepared Via Chemical Precipitation Method. Int. J. Curr. Eng. Sci. Res. 2019, 6, $438-441$.

34. Megala, R.; Gowthami, T.; John Sushma, N.; Kamala, S.; Deva Prasad Raju, B. A study of low threshold and high gain Nd ions doped $\mathrm{SiO}_{2}-\mathrm{B}_{2} \mathrm{O}_{3}-\mathrm{Na}_{2} \mathrm{CO}_{3}-\mathrm{NaF}-\mathrm{CaF}_{2}$ glasses for NIR laser applications. Infrared Phys. Technol. 2018, 90, 221-229. [CrossRef]

35. Jaidev, L.R.; Narasimha, G. Fungal mediated biosynthesis of silver nanoparticles, characterization and antimicrobial activity. Colloids Surf. B Biointerfaces 2010, 81, 430-433. [CrossRef]

36. Srihasam, S.; Thyagarajan, K.; Mallikarjuna, K.; Lebaka, V.R.; Mallem, S.P.R. Phytogenic Generation of NiO Nanoparticles Using Stevia Leaf Extract and Evaluation of Their In-Vitro Antioxidant and Antimicrobial Properties. Biomolecules 2020, 10, 89. [CrossRef] 